\title{
Effects of Smoking and Smoking Cessation on Lipids and Lipoproteins: Outcomes from a Randomized Clinical Trial
}

\author{
Adam D. Gepner, MD, Megan E. Piper, PhD, Heather M. Johnson, MD, Michael C. Fiore, MD, \\ MPH, Timothy B. Baker, PhD, and James H. Stein, MD \\ University of Wisconsin School of Medicine and Public Health; Madison, WI
}

\begin{abstract}
Background-The effects of smoking and smoking cessation on lipoproteins have not been studied in a large contemporary group of smokers. This study was designed to determine the effects of smoking cessation on lipoproteins.
\end{abstract}

\begin{abstract}
Methods-One-year, prospective, double-blind, randomized, placebo-controlled clinical trial of the effects of 5 smoking cessation pharmacotherapies. Fasting nuclear magnetic resonance spectroscopy lipoprotein profiles were obtained before and 1-year after the target smoking cessation date. The effects of smoking cessation and predictors of changes in lipoproteins after one year were identified by multivariable regression.

Results-The 1,504 current smokers were mean (standard deviation) 45.4 (11.3) years old and smoked 21.4 (8.9) cigarettes/day at baseline. Of the 923 adult smokers who returned at 1 year, 334 (36.2\%) had quit smoking. Despite gaining more weight (4.6 kg [5.7] vs. $0.7 \mathrm{~kg}$ [5.1], p<0.001], abstainers had increases in high-density lipoprotein cholesterol (HDL-C) (2.4 [8.3] vs. 0.1 [8.8] $\mathrm{mg} / \mathrm{dL}, \mathrm{p}<0.001$ ], total HDL (1.0 [4.6] vs. $-0.3 \mathrm{mcmol} / \mathrm{L}$ [5.0], $\mathrm{p}<0.001)$ and large HDL $(0.6$ [2.2] vs. $0.1[2.1] \mathrm{mcmol} / \mathrm{L}, \mathrm{p}=0.003)$ particles, compared with continuing smokers. Significant changes in low-density lipoprotein (LDL) cholesterol and particles were not observed. After adjustment, abstinence from smoking $(\mathrm{p}<0.001)$ was independently associated with increases in HDL-C and total HDL particles. These effects were stronger in women.
\end{abstract}

Conclusions-Despite weight gain, smoking cessation improved HDL-C, total HDL and large HDL particles, especially in women. Smoking cessation did not affect LDL or LDL size. Increases in HDL may mediate part of the reduced cardiovascular disease risk observed after smoking cessation.

\section{Keywords}

Clinical Trial; High-density lipoprotein cholesterol; Lipoproteins; Low-density lipoprotein cholesterol; Risk Factors; Smoking

\footnotetext{
Address for Correspondence: James H. Stein, MD, University of Wisconsin School of Medicine and Public Health, 600 Highland Avenue, G7/341 CSC (MC 3248), Madison, WI 53792, Phone: (608) 263-9648, Fax: (608) 263-0405, jhs@ medicine.wisc.edu.

Potential Conflicts of Interest

AD Gepner, ME Piper, HM Johnson, JH Stein - no conflicts to disclose.

MC Fiore - Over the last three years, Dr Fiore has served as an investigator in research studies at the University of Wisconsin that were funded by Pfizer, GlaxoSmithKline and Nabi Biopharmaceuticals. In 1998, the University of Wisconsin (UW) appointed Dr. Fiore to a named Chair funded by an unrestricted gift to UW from Glaxo Wellcome.

TB Baker - Research grants from Pfizer, GlaxoSmithKline, Nabi Biopharmaceuticals, and Sanofi.
} 


\section{Background}

Each year, smoking contributes to more than 443,000 smoking related deaths in the United States ${ }^{1}$ and nearly $20 \%$ of all coronary heart disease deaths can be attributed to smoking. ${ }^{1,2}$ Although the strong relationship between smoking and cardiovascular disease (CVD) has been well-documented, ${ }^{3,4}$ the mechanisms by which smoking increases CVD risk appear to be multifactorial and incompletely understood, in part because these associations have been derived from observational studies. ${ }^{5-8}$ These studies, and smaller clinical trials, suggest that cigarette smoking is associated with a more atherogenic lipid profile ${ }^{6,8,9}$ characterized by higher total cholesterol and triglycerides with lower levels of high-density lipoprotein cholesterol (HDL-C).

Smoking intensity also has been associated with small, statistically significant increases in low-density lipoprotein cholesterol (LDL-C) and decreases in HDL-C. ${ }^{6,8,10}$ Some have described small dense LDL particles among current smokers and improvements in lipids after smoking cessation; however, these findings have been less consistent. ${ }^{11,12}$ No studies, to date, have prospectively evaluated the effects of continued smoking and smoking cessation on lipoproteins in a large, contemporary cohort of current smokers. This is a matter of considerable importance, because smokers in the $21^{\text {st }}$ century are significantly more overweight than those studied previously. ${ }^{6,8,13}$ Since smoking cessation is associated with weight gain ${ }^{14-16}$ and weight gain affects lipoproteins, $, 8,17,18$ the effects of smoking cessation on lipoproteins remains unclear.

We evaluated the effects of current smoking and smoking cessation on lipids and lipoproteins in a prospective, randomized clinical trial of smoking cessation pharmacotherapy. 19

\section{Methods}

\section{Study Participants and Design}

The institutional review board at the University of Wisconsin School of Medicine and Public Health approved this study. All subjects provided informed consent. Subjects were participants in a randomized, double-blind, placebo-controlled trial to evaluate the efficacy of smoking cessation pharmacotherapies and to examine the natural history of continued smoking and smoking cessation on CVD risk (clinicaltrials.gov registration number NCT00332644). ${ }^{19}$ Specific recruitment strategies have been described previously. ${ }^{19}$ This manuscript describes the effects of smoking cessation and continued smoking on lipids and lipoprotein subfractions one year after the target quit date, a pre-specified analysis in this study. The authors are solely responsible for the design and conduct of this study; all study analyses, the drafting and editing of the paper and its final contents.

Participants were randomized to one of six treatment conditions: nicotine lozenge, nicotine patch, sustained-release bupropion, nicotine patch plus nicotine lozenge, sustained-release bupropion plus nicotine lozenge, or placebo. ${ }^{19}$ All participants received individual cessation counseling. ${ }^{19}$ Major inclusion criteria were: age $\geq 18$ years, smoking $\geq 10$ cigarettes/day, expired carbon monoxide (CO) level $>9 \mathrm{ppm}$, and stated motivation to quit smoking. Exclusion criteria have been reported previously; ${ }^{19}$ the major ones were: blood pressure (BP) $>160 / 100 \mathrm{mmHg}$, recent myocardial infarction, heavy alcohol use, use of contraindicated medications, and current pregnancy or breast-feeding.

\section{Study Procedures}

Subjects were recruited from communities in and around Madison and Milwaukee, Wisconsin from January, 2005 to June, 2007. ${ }^{19}$ The baseline clinical trial visits included 
measurement of anthropometric data, fasting laboratory tests, and completion of questionnaires and interviews. Baseline physical activity was assessed by the International Physical Activity Questionnaire. ${ }^{20}$ Baseline alcohol use was measured as alcoholic drinks consumed per month. ${ }^{21}$ Smoking burden was evaluated by current cigarette smoking (cigarettes/day) and pack-years (current cigarettes/day * years smoked). Recent smoke exposure was measured by an exhaled $\mathrm{CO}$ level, which reflects smoking efficiency and recent smoke exposure. Smoking status was assessed by self-reported 7-day pointprevalence abstinence using a smoking calendar and the timeline follow-back method, confirmed by an exhaled CO level of $<10$ ppm (Micro-3 Smokerlyzer, Bedfont Scientific, Williamsburg, VA). ${ }^{21,22}$

\section{Measurement of Lipids and Lipoproteins}

Fasting blood samples were obtained by venipuncture and refrigerated. Plasma aliquots were isolated by centrifugation and frozen at -70 degrees. Samples underwent nuclear magnetic resonance spectroscopic lipoprotein analysis (Lipoprofile-2, LipoScience, Inc., Raleigh, NC) using previously published methods ${ }^{23}$ Concentrations of very low-density lipoprotein (VLDL) and LDL (including intermediate-density lipoprotein) subclasses (in $\mathrm{nmol} / \mathrm{L}$ ) and HDL subclasses (in $\mathrm{mcmol} / \mathrm{L}$ ) were determined. The 9 measured subclasses were defined as follows: large VLDL (>60 nm), medium VLDL (35-60 nm), small VLDL (27-35 nm), intermediate-density lipoprotein (IDL, 23-27 nm), large LDL (21.2-23.0 nm), small LDL (18.0-21.2 nm), large HDL (8.8-13.0 nm), medium HDL (8.2-8.8 nm), and small HDL $(7.3-8.2 \mathrm{~nm})$. Total LDL particle concentrations are the sum of the intermediate-density lipoprotein, large LDL, and small LDL subclass concentrations. Total HDL particle concentrations are the sum of large, medium, and small HDL subclass concentrations. Weighted-average LDL and HDL particle sizes were determined by summing the diameter of each subclass multiplied by its relative mass percentage as estimated by the amplitude of its methyl NMR signal. ${ }^{23,24}$ Nuclear magnetic resonance-derived cholesterol $(-\mathrm{C})$ and triglycerides (TG) were determined by conversion of lipoprotein particle data to lipid concentration units $(\mathrm{mg} / \mathrm{dL})$ based on the expected amount of cholesterol and triglycerides in each particle. ${ }^{23}$

\section{Statistical Analysis}

All analyses were conducted using PASW Statistics 18 software (SPSS Inc, Chicago, IL). Means (standard deviations) were determined for the subject characteristics and smoking intensity parameters in Table I. Variable disributions were evaluated for normality. Skewed variables (TG, alcohol consumption, and IPAQ activity scores) were log-transformed. Pearson correlations were used to identify univariate associations between age, sex, bodymass index (BMI), waist circumference, weight, glucose, baseline cigarettes/day, baseline physical activity, and baseline alcohol use with lipids and lipoproteins at baseline and after 1 -year. Changes were computed by subtracting year 1 from baseline values. T-tests were used to compare change scores for BMI, weight, waist circumference, glucose, CO levels, and the lipid and lipoprotein measures between participants who were abstinent at one year and those who were smoking.

Multivariable linear regression models were constructed to determine associations of changes in lipids and lipoproteins from baseline to one year after the target quit date. Separate models were created for predicting changes in each lipid fraction hypothesized to be influenced by smoking status (HDL-C, LDL-C, and TG) and selected lipoprotein measures chosen because of established relationships with smoking and/or CVD risk (total LDL particles, small LDL particles, LDL size, total HDL particles, large HDL particles, HDL size). Because there were 9 lipid and lipoprotein variables of interest, a Bonferronicorrected $\alpha<0.0056$ was used to control for Type I error. For other variables, a standard 
$\alpha<0.05$ was used. Each model was adjusted for baseline values of each lipid or lipoprotein parameter. All models included covariates that could affect the dependent variables independently of smoking cessation, such as age, sex, race, weight change, treatment arm, baseline cigarettes/day, baseline physical activity, baseline alcohol consumption, smoking status at year one (abstinent or continued smoker), and change in glucose level. Change in weight was used as rather than change in BMI or waist circumference it had the strongest univariate associations with changes in the lipoprotein parameters. Multivariable models are described using R-squared values and beta coefficients. Partial regression plots of change in HDL-C by quartile of baseline cigarettes/day and quintile of baseline $\mathrm{CO}$ (adjusted for change in weight and baseline HDL-C) also were examined to determine if changes in HDL$\mathrm{C}$ among abstainers were related to baseline smoking intensity.

\section{Funding Sources}

This study was supported by grant P50 DA019706 from the National Institute on Drug Abuse to the University of Wisconsin-Center for Tobacco Research and Intervention. Dr. Piper was supported by an Institutional Clinical and Translational Science Award KL2 RR025012. Dr. Johnson was supported by grant T32 HL07936 from the National Heart Lung and Blood Institute. Dr. Baker was supported by grant K05CA139871 from the National Cancer Institute. Medications were provided by GlaxoSmithKline. The authors are solely responsible for the design and conduct of this study, all study analyses, the drafting and editing of the paper and its final contents.

\section{Results}

\section{Subject Characteristics}

Subject characteristics at baseline and year one are provided in Table I. There were 1,504 smoking subjects randomized. As often observed in smoking cessation clinical trials, ${ }^{25-27}$ $581(39 \%)$ subjects did not return for their 1-year follow-up visit. Individuals who returned for this visit were slightly older (mean 1.2 years, $\mathrm{p}<0.001$ ) and had slightly higher HDL-C (mean $1.4 \mathrm{mg} / \mathrm{dL}, \mathrm{p}=0.041$ ) than those who did not return, but otherwise had similar CO levels, waist circumference, serum glucose, total cholesterol, triglycerides, LDL-C, and hsCRP (all P>0.20). ${ }^{15,28}$

Of the 923 subjects who attended the Year 1 visit, 58\% were women, $84 \%$ were white and $13 \%$ were African-American. Abstinence from smoking was confirmed in 334 (36.2\%) participants. Only 5\% were using lipid-lowering medications. Excluding these subjects did not change the results significantly (data not shown). Only $2.8 \%$ of subjects had hemoglobin $\mathrm{A}_{1} \mathrm{C}>7 \% ; 14.4 \%$ had hemoglobin $\mathrm{A}_{1} \mathrm{C}>6 \%$, percentages similar to the proportions of smokers with values above these thresholds in the 2005-2006 National Health and Nutrition Examination Survey (Personal Communication: Jon Keevil and Matt Tattersall, 9/1/2010). Additionally, 11 subjects self-reported a diagnosis of diabetes mellitus. Baseline alcohol use and physical activity level were similar for abstainers and continued smokers. At baseline, the subjects performed 122.0 (150.1) metabolic equivalent-hours/day of moderate-vigorous activity and 11.1 (21.4) metabolic equivalent -hours/day of leisure activity. ${ }^{15}$ Compared to those who relapsed, abstainers had slightly lower baseline CO levels (23.4 [11.1] vs. 26.4 [12.3] ppm, $\mathrm{p}<0.001)$, smoked fewer cigarettes per day (20.0 [8.7] vs. 21.8 [9.2], $\mathrm{p}=0.003$ ), and had fewer pack-years (27.3 [19.9] vs. 30.7 [21.1], p=0.014). Baseline levels of all lipid and lipoprotein parameters were similar for abstainers and continued smokers except for small HDL particles which were slightly higher at baseline in those who abstained (24.1 [4.5] vs. 23.4 [5.1] mcmol/L, p=0.035) (Table I). 


\section{Effects of Smoking Cessation}

Comparisons between abstainers and continuing smokers are summarized in Table I. After one year, $\mathrm{CO}$ levels decreased both in abstainers and continued smokers; however, subjects who abstained had significantly greater $\mathrm{CO}$ reductions $(-21.3[11.2]$ vs. $-7.2[13.0] \mathrm{ppm}$, $\mathrm{p}<0.001)$. Compared to continued smokers, abstainers had more weight gain (4.6 [5.7] vs. $0.7[5.1] \mathrm{kg}, \mathrm{p}<0.001)$ and greater increases in waist circumference $(2.8$ [10.6] vs. 1.0 [6.3] $\mathrm{cm}, \mathrm{p}<0.001)$, and BMI (1.6[2.0] vs. $\left.0.2[1.7] \mathrm{kg} / \mathrm{m}^{2}, \mathrm{p}<0.0010\right)$. Abstainers had significant increases in HDL-C (2.4 [8.3] vs. 0.1 [8.8] mg/dL, p<0.001), total HDL particles (1.0 [4.6] vs. $-0.3[5.0] \mathrm{mcmol} / \mathrm{L}, \mathrm{p}<0.001)$ and large HDL particles $(0.6$ [2.2] vs. $0.1[2.1] \mathrm{mcmol}$, $\mathrm{p}=0.003$ ) compared to those who continued to smoke (Figure). Statistically significant differences in other lipid and lipoprotein fractions were not observed.

\section{Independent Associations with Change in HDL Parameters}

Models to identify independent predictors of changes in HDL-C and particles are described in Table II. All analyses were adjusted for baseline values of each lipid or lipoprotein parameter, as well as the parameters described in the Methods. As expected, the most powerful predictors of changes in the HDL-related parameters were baseline values, with larger changes among those with the lowest baseline levels of HDL-C, total HDL particles, large HDL particles, and the smallest HDL diameters. For HDL-C, total HDL particles and large HDL particles, the next most powerful predictors were abstinence from smoking and female sex, except for HDL particle size, for which change in weight was nearly as powerful a predictor as baseline HDL diameter. In abstainer, neither baseline number of cigarettes smoked per day $(\mathrm{p}=0.834)$ nor baseline $\mathrm{CO}$ levels $(\mathrm{p}=0.107)$ predicted changes in any HDLrelated parameter after adjustment for changes in weight and baseline HDL-C.

\section{Discussion}

To our knowledge this is the largest prospective, randomized clinical trial that has evaluated the effects of smoking cessation on lipid and lipoprotein levels. Although smoking is associated with low HDL-C, previous studies suggesting that smoking cessation increases HDL-C levels were from older, observational studies with less contemporary cohorts or from smaller clinical trials. Smokers in our study had higher BMIs than in previous reports, and are more representative of the current United States population. ${ }^{6,8,9,13,29}$ Despite our subjects being more overweight and gaining weight after smoking cessation, we showed that smoking cessation was related to higher HDL-C and higher total and large HDL particles. Patients with the lowest HDL-related parameters had the largest increases in HDL. After baseline levels of HDL-C and HDL particles, abstinence from cigarette smoking was the next most powerful predictor of changes in these parameters, followed by female sex and weight change. The observation that women had larger increases in HDL-C and HDL particles after smoking cessation is consistent with our previous observation that among current smokers, the association between pack-years of smoking and the presence of carotid plaque was stronger in women, ${ }^{30}$ and a previous observation that smoking has a stronger association with coronary heart disease incidence in women compared to men. ${ }^{31}$

The mechanisms by which smoking decreases HDL-C are incompletely understood. Smoking increases catecholamine release, causing a surge in circulating free fatty acids, which may increase VLDL and LDL concentrations and reduce HDL-C concentrations. ${ }^{8}$ Smoking reduces lecithin-cholesterol acyl-transferase, the enzyme responsible for esterifying free cholesterol and increasing HDL size, ${ }^{32}$ and may reduce levels of cholesterol ester transfer protein; however, studies of the effects smoking on these enzymes have had mixed results. ${ }^{33-35}$ In population-based studies, a $1 \mathrm{mg} / \mathrm{dL}$ increase in HDL-C has been associated with a 2-3\% decrease in CVD events. ${ }^{36,37}$ This implies that in our subjects, 
smoking abstinence could reduce CVD events by $4-6 \%$ over a decade. Our study also suggests that abstinence from smoking is associated with increases in HDL-C, regardless of baseline smoking intensity. This important finding may encourage clinicians to emphasize abstinence even in light smokers.

Weight gain after smoking cessation can be a significant barrier to quitting. ${ }^{14-16}$ In our study, those who abstained gained approximately $4 \mathrm{~kg}$ more than those who resumed smoking. Increased weight has been associated with lower HDL-C, such that every kilogram of additional weight can reduce HDL-C by $0.5-1 \% ;{ }^{17,18}$ however, HDL-C increased by $5.2 \%$ among abstainers in our study. Weight gain was independently associated with increased HDL-C as well as total and large HDL particles. This suggests that the impact of weight gain on HDL may be counteracted by the impact of smoking cessation. This important finding has not been reported previously in a cohort of this size. Smoking has been associated with increased triglycerides. ${ }^{6}$ In our study, abstinence from smoking was associated with only mild triglycerides reductions that were not statistically significant after correcting for multiple comparisons, likely because of the counterbalancing effect of weight gain. Significant changes in LDL-C, LDL particle concentrations, and LDL size were not observed.

\section{Limitations}

Because this was a randomized clinical trial of smoking cessation interventions, there were no non-smoking controls, so we cannot determine the extent to which lipoprotein values normalized after smoking cessation. In smoking cessation studies, it is common for subjects who relapse to drop out or miss follow-up visits. ${ }^{25-27}$ In our study, $38.6 \%$ of subjects did not return for their one year follow-up visit, which is consistent with the 30-43\% one year dropout rates reported in other recent clinical trials of smoking cessation pharmacotherapy. ${ }^{26,27}$ Subjects who did not attend the follow-up visit had similar age, sex, and race distributions to those that did return, and they smoked a similar number of cigarettes/day at baseline. ${ }^{15}$ Although significant efforts were made to recruit racially diverse participants, only $16 \%$ of the study cohort was non-white. Also, changes in alcohol use and physical activity levels were not included in the analysis because 1-year follow-up data were not yet coded for analysis. Alcohol use and exercise can increase HDL-C levels. Smoking cessation is not associated with increased exercise levels; however, we cannot exclude the possibility that the increases in HDL we observed among abstainers were related to increased alcohol intake. Most smoking cessation trials have not systematically evaluated alcohol use. ${ }^{38}$ Smoking cessation studies that did evaluate alcohol use have had conflicting results; 39,40 however, our statistical models did not show that baseline exercise levels or alcohol use independently predicted changes in HDL parameters. Although LDL particles and LDL-C did not change significantly with smoking cessation, we did not measure oxidized LDL levels.

\section{Conclusion}

In this large, prospective, contemporary study of current smokers, smoking cessation improved HDL-C, total HDL, and large HDL particle concentrations, despite weight gain. These findings were especially strong in women. Smoking cessation, not baseline smoking intensity, predicted increased HDL parameters. These findings suggest that an increase in HDL may mediate some of the reduced CVD risk observed after smoking cessation.

\section{Abbreviations}

BMI body-mass index 


$\begin{array}{ll}\text { BP } & \text { blood pressure } \\ - \text { C } & \text { cholesterol } \\ \text { CO } & \text { carbon monoxide } \\ \text { CVD } & \text { cardiovascular disease } \\ \text { HDL } & \text { high-density lipoprotein } \\ \text { LDL } & \text { low-density lipoprotein } \\ \text { TG } & \text { triglycerides } \\ \text { VLDL } & \text { very-low density lipoproteins }\end{array}$

\section{Reference List}

1. Center for Disease Control and Prevention. Smoking-Attributable Mortality, Years of Potential Life Lost, and Productivity Losses - United States. 2002-2004 [accessed 2009 Apr 8]. Morbidity and Mortality Weekly Report. 2008; 57:1226-28. [PubMed: 19008791]

2. American Heart Association. Heart Disease and Stroke Statistics--2009 Update. Dallas, TX: American Heart Association; 2009.

3. Doll R, Peto R, Boreham J, et al. Mortality in relation to smoking: 50 years' observations on male British doctors. BMJ. 2004; 328:1519. [PubMed: 15213107]

4. Freund KM, Belanger AJ, D'Agostino RB, et al. The health risks of smoking. The Framingham Study: 34 years of follow-up. Ann Epidemiol. 1993; 3:417-24. [PubMed: 8275219]

5. Ambrose JA, Barua RS. The pathophysiology of cigarette smoking and cardiovascular disease: an update. J Am Coll Cardiol. 2004; 43:1731-37. [PubMed: 15145091]

6. Gossett LK, Johnson HM, Piper ME, et al. Smoking Intensity and Lipoprotein Abnormalities in Active Smokers. J Clin Lipidol. 2009; 3:372-78. [PubMed: 20161531]

7. Benowitz NL. Cigarette smoking and cardiovascular disease: pathophysiology and implications for treatment. Prog Cardiovasc Dis. 2003; 46:91-111. [PubMed: 12920702]

8. Campbell SC, Moffatt RJ, Stamford BA. Smoking and smoking cessation - The relationship between cardiovascular disease and lipoprotein metabolism: A review. Atherosclerosis. 2008; 201:225-35. [PubMed: 18565528]

9. Craig WY, Palomaki GE, Haddow JE. Cigarette smoking and serum lipid and lipoprotein concentrations: an analysis of published data. BMJ. 1989; 298:784-88. [PubMed: 2496857]

10. Criqui MH, Wallace RB, Heiss G, et al. Cigarette smoking and plasma high-density lipoprotein cholesterol. The Lipid Research Clinics Program Prevalence Study. Circulation. 1980; 62:IV70IV76. [PubMed: 7418146]

11. Griffin BA, Freeman DJ, Tait GW, et al. Role of plasma triglyceride in the regulation of plasma low density lipoprotein (LDL) subfractions: relative contribution of small, dense LDL to coronary heart disease risk. Atherosclerosis. 1994; 106:241-53. [PubMed: 8060384]

12. Urahama N, Iguchi G, Shimizu M, et al. Smoking and small, dense low-density lipoprotein particles: cross-sectional study. Nicotine Tob Res. 2008; 10:1391-95. [PubMed: 18686187]

13. Center for Disease Control and Prevention. State-Specific Prevalence of Obesity Among Adults-United States, 2007. Morbidity and Mortality Weekly Report. 2008; 57:765-68. [PubMed: 18636063]

14. Eisenberg D, Quinn BC. Estimating the effect of smoking cessation on weight gain: an instrumental variable approach. Health Serv Res. 2006; 41:2255-66. [PubMed: 17116119]

15. Johnson HM, Gossett LK, Piper ME, et al. Effects of smoking and smoking cessation on endothelial function: 1-year outcomes from a randomized clinical trial. J Am Coll Cardiol. 2010; 55:1988-95. [PubMed: 20236788]

16. Flegal KM, Troiano RP, Pamuk ER, et al. The influence of smoking cessation on the prevalence of overweight in the United States. N Engl J Med. 1995; 333:1165-70. [PubMed: 7565970] 
17. Dattilo AM, Kris-Etherton PM. Effects of weight reduction on blood lipids and lipoproteins: a meta-analysis. Am J Clin Nutr. 1992; 56:320-328. [PubMed: 1386186]

18. Hession M, Rolland C, Kulkarni U, et al. Systematic review of randomized controlled trials of lowcarbohydrate vs. low-fat/low-calorie diets in the management of obesity and its comorbidities. Obes Rev. 2009; 10:36-50. [PubMed: 18700873]

19. Piper ME, Smith SS, Schlam TR, et al. A randomized placebo-controlled clinical trial of 5 smoking cessation pharmacotherapies. Arch Gen Psychiatry. 2009; 66:1253-62. [PubMed: 19884613]

20. Craig CL, Marshall AL, Sjostrom M, et al. International physical activity questionnaire: 12-country reliability and validity. Med Sci Sports Exerc. 2003; 35:1381-95. [PubMed: 12900694]

21. Sobell LC, Sobell MB, Leo GI, et al. Reliability of a timeline method: assessing normal drinkers' reports of recent drinking and a comparative evaluation across several populations. Br J Addict. 1988; 83:393-402. [PubMed: 3395719]

22. Brigham J, Lessov-Schlaggar CN, Javitz HS, et al. Reliability of adult retrospective recall of lifetime tobacco use. Nicotine Tob Res. 2008; 10:287-99. [PubMed: 18236293]

23. Jeyarajah EJ, Cromwell WC, Otvos JD. Lipoprotein particle analysis by nuclear magnetic resonance spectroscopy. Clin Lab Med. 2006; 26:847-70. [PubMed: 17110242]

24. Rifai, N.; Warnick, GR.; Dominiczak, MH., editors. Handbook of Lipoprotein Testing. 2. Washington, DC: AACC Press; 2000. p. 617-18.

25. Hall SM, Delucchi KL, Velicer WF, et al. Statistical analysis of randomized trials in tobacco treatment: longitudinal designs with dichotomous outcome. Nicotine Tob Res. 2001; 3:193-202. [PubMed: 11506764]

26. Jorenby DE, Hays JT, Rigotti NA, et al. Efficacy of varenicline, an alpha4beta2 nicotinic acetylcholine receptor partial agonist, vs placebo or sustained-release bupropion for smoking cessation: a randomized controlled trial. JAMA. 2006; 296:56-63. [PubMed: 16820547]

27. Gonzales D, Rennard SI, Nides M, et al. Varenicline, an alpha4beta2 nicotinic acetylcholine receptor partial agonist, vs sustained-release bupropion and placebo for smoking cessation: a randomized controlled trial. JAMA. 2006; 296:47-55. [PubMed: 16820546]

28. Asthana A, Johnson HM, Piper ME, et al. Effects of smoking intensity and cessation on inflammatory markers in a large cohort of active smokers. Am Heart J. 2010; 160:458-63. [PubMed: 20826253]

29. Maeda K, Noguchi Y, Fukui T. The effects of cessation from cigarette smoking on the lipid and lipoprotein profiles: a meta-analysis. Prev Med. 2003; 37:283-90. [PubMed: 14507483]

30. Johnson HM, Piper M, Jorenby D, Baker T, Fiore MC, Stein JH. Risk factors for subclinical atherosclerosis among current smokers. Preventive Cardiology. 2010 (in press).

31. Richey SA, Coady SA, Folsom AR, et al. Smoking and diabetes differ in their associations with subclinical atherosclerosis and coronary heart disease-the ARIC Study. Atherosclerosis. 2004; 172:143-49. [PubMed: 14709368]

32. McCall MR, van den Berg JJ, Kuypers FA, et al. Modification of LCAT activity and HDL structure. New links between cigarette smoke and coronary heart disease risk. Arterioscler Thromb. 1994; 14:248-53. [PubMed: 8305416]

33. Freeman DJ, Griffin BA, Murray E, et al. Smoking and plasma lipoproteins in man: effects on low density lipoprotein cholesterol levels and high density lipoprotein subfraction distribution. Eur J Clin Invest. 1993; 23:630-640. [PubMed: 8281981]

34. Zaratin AC, Quintao EC, Sposito AC, et al. Smoking prevents the intravascular remodeling of high-density lipoprotein particles: implications for reverse cholesterol transport. Metabolism. 2004; 53:858-62. [PubMed: 15254877]

35. Freeman DJ, Caslake MJ, Griffin BA, et al. The effect of smoking on post-heparin lipoprotein and hepatic lipase, cholesteryl ester transfer protein and lecithin:cholesterol acyl transferase activities in human plasma. Eur J Clin Invest. 1998; 28:584-91. [PubMed: 9726040]

36. Gordon DJ, Probstfield JL, Garrison RJ, et al. High-density lipoprotein cholesterol and cardiovascular disease. Four prospective American studies. Circulation. 1989; 79:8-15. [PubMed: 2642759] 
37. Grover SA, Kaouache M, Joseph L, et al. Evaluating the incremental benefits of raising highdensity lipoprotein cholesterol levels during lipid therapy after adjustment for the reductions in other blood lipid levels. Arch Intern Med. 2009; 169:1775-80. [PubMed: 19858435]

38. Toll BA, Leeman RF, McKee SA, et al. A brief 7-day estimate of alcohol consumption for use in smoking cessation clinical trials. Addict Behav. 2008; 33:1606-9. [PubMed: 18722721]

39. Friend KB, Pagano ME. Smoking cessation and alcohol consumption in individuals in treatment for alcohol use disorders. J Addict Dis. 2005; 24:61-75. [PubMed: 15784524]

40. Breitling LP, Muller H, Raum E, et al. Low-to-moderate alcohol consumption and smoking cessation rates: retrospective analysis of 4576 elderly ever-smokers. Drug Alcohol Depend. 2010; 108:122-29. [PubMed: 20061096] 


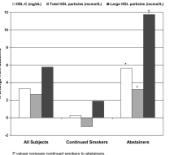

Figure.

Percent Change in HDL Parameters at 1-year Compared to Baseline Values $P$ values compare continued smokers to abstainers.

$* \mathrm{p}<0.001 ; \dagger \mathrm{p}=0.002$ 


\begin{tabular}{|c|c|c|c|c|c|c|c|c|c|c|c|c|c|c|c|c|c|c|c|c|c|}
\hline & $\begin{array}{l}y< \\
\dot{i} \\
\dot{y}\end{array}$ & 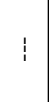 & 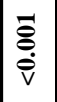 & 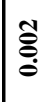 & 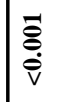 & 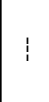 & 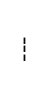 & \begin{tabular}{|c|}
$\bar{\Xi}$ \\
$\stackrel{\vec{v}}{v}$
\end{tabular} & $\frac{\sigma}{\sigma}$ & $\mid \begin{array}{l}\frac{H}{d} \\
\stackrel{0}{0}\end{array}$ & \begin{tabular}{|l|}
$\infty$ \\
$\stackrel{0}{0}$ \\
$\stackrel{0}{0}$
\end{tabular} & $\begin{array}{l}0 \\
0 \\
0 \\
0\end{array}$ & $\begin{array}{l}\text { on } \\
\text { nn? }\end{array}$ & \begin{tabular}{l}
$\infty$ \\
\multirow{6}{0}{} \\
0
\end{tabular} & $\begin{array}{c}\mathscr{\infty} \\
\infty \\
\infty \\
0\end{array}$ & 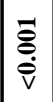 & 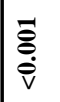 & 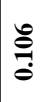 & 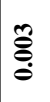 & 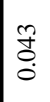 & $\overrightarrow{8}$ \\
\hline & 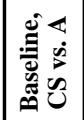 & t: & $\mid \begin{array}{c}\tilde{b} \\
\vdots \\
0 \\
0\end{array}$ & 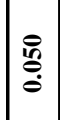 & $\frac{n}{0}$ & : & $\stackrel{t}{0}$ & \begin{tabular}{|l}
$\bar{\Xi}$ \\
$\grave{\hat{v}}$
\end{tabular} & $\frac{\widetilde{\sigma}}{0}$ & 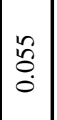 & \begin{tabular}{l}
0 \\
\multirow{1}{0}{} \\
0
\end{tabular} & $\overrightarrow{\tilde{f}}$ & $\stackrel{n}{\rightleftarrows}$ & & & $\mid \begin{array}{c}\mathbb{N} \\
\infty \\
0 \\
0\end{array}$ & ర్లి & & & $\stackrel{+}{ \pm}$ & \\
\hline
\end{tabular}

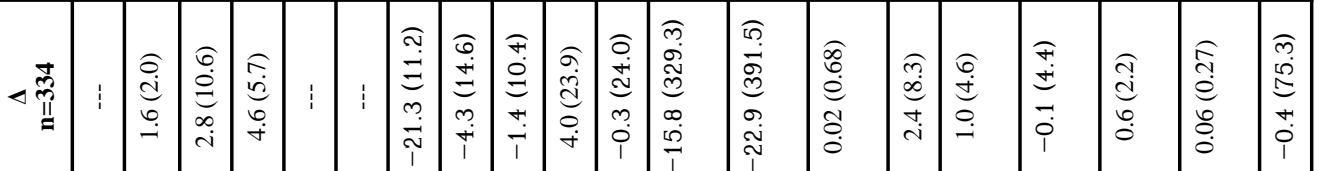

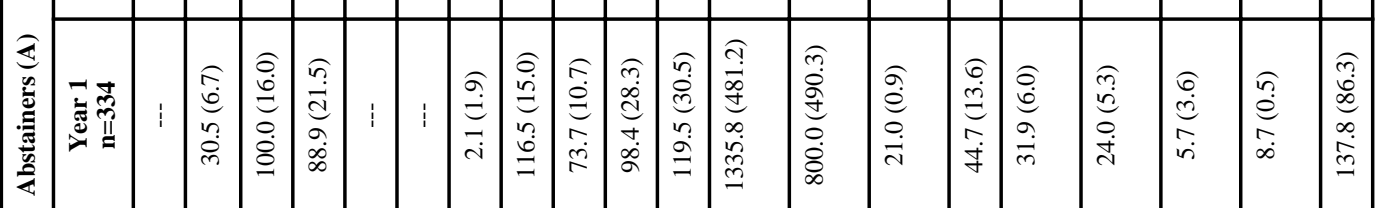

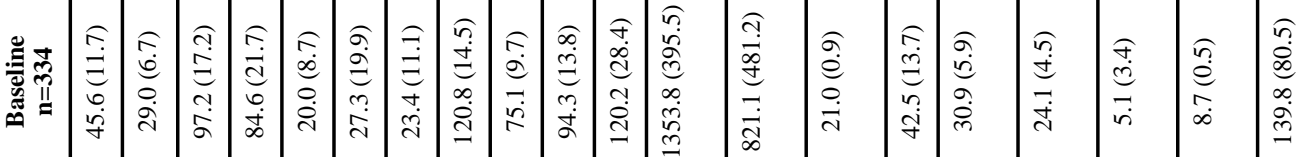

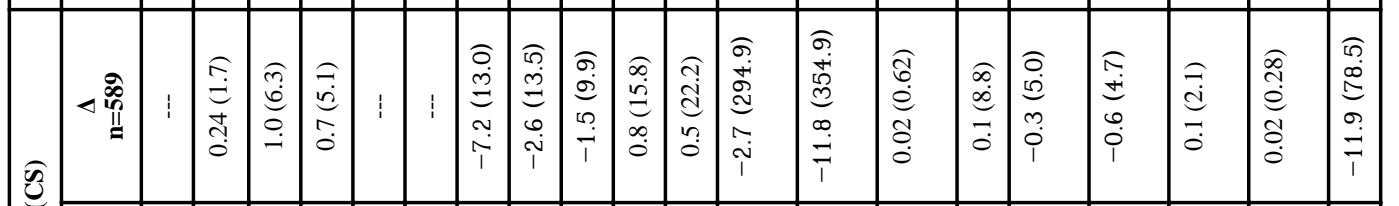

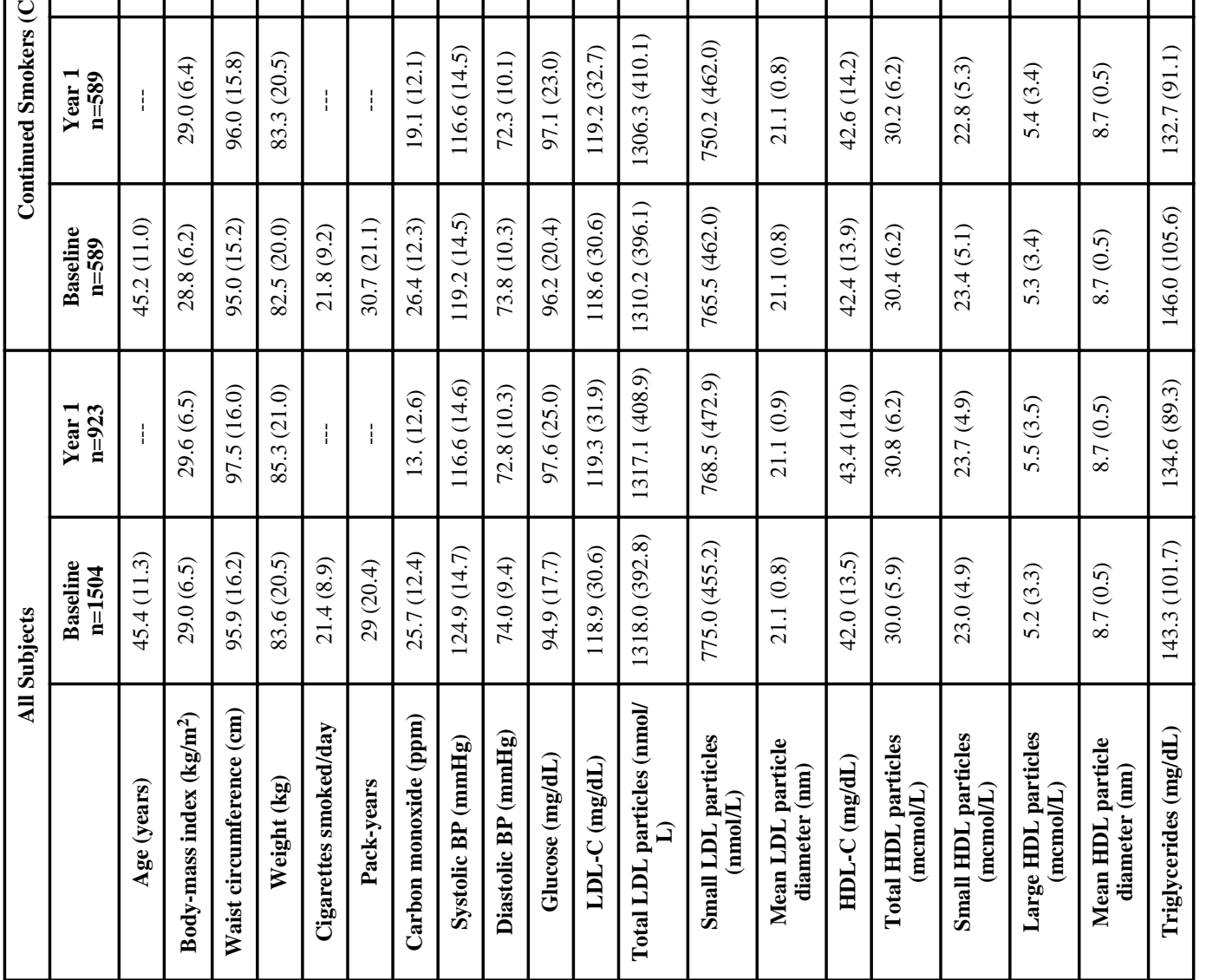




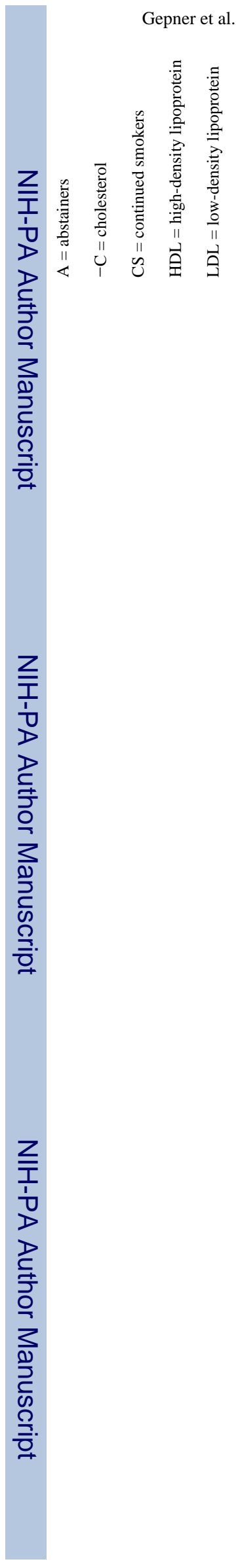

Page 12

Am Heart J. Author manuscript; available in PMC 2012 January 1. 
Table II

Significant Predictors of Changes in Lipoprotein Parameters from Baseline to 1 Year

\begin{tabular}{|c|c|c|c|c|}
\hline Dependent variable & Adjusted $\mathbf{R}^{2}$ & Significant Independent Predictors & Standardized $\beta$ & P Value \\
\hline \multirow{4}{*}{$\Delta$ HDL-C } & \multirow{4}{*}{0.101} & Baseline HDL-C & -0.299 & $<0.001$ \\
\hline & & Abstinence status & 0.195 & $<0.001$ \\
\hline & & Female sex & 0.140 & $<0.001$ \\
\hline & & $\Delta$ weight (kg) & 0.130 & 0.001 \\
\hline \multirow{3}{*}{$\Delta$ Total HDL particles } & \multirow{3}{*}{0.141} & Baseline total HDL particles & -0.376 & $<0.001$ \\
\hline & & Abstinence status & 0.161 & $<0.001$ \\
\hline & & Female sex & 0.108 & 0.003 \\
\hline \multirow{4}{*}{$\Delta$ Large HDL particles } & \multirow{4}{*}{0.110} & Baseline large HDL particles & -0.322 & $<0.001$ \\
\hline & & Abstinence status & 0.170 & $<0.001$ \\
\hline & & Female sex & 0.151 & $<0.001$ \\
\hline & & $\Delta$ weight $(\mathrm{kg})$ & 0.133 & $<0.001$ \\
\hline \multirow{4}{*}{$\Delta$ HDL particle diameter } & \multirow{4}{*}{0.125} & Baseline HDL particle diameter & -0.281 & $<0.001$ \\
\hline & & $\Delta$ weight $(\mathrm{kg})$ & 0.256 & $<0.001$ \\
\hline & & Abstinence status & 0.162 & $<0.001$ \\
\hline & & Female sex & 0.106 & 0.006 \\
\hline
\end{tabular}

Models included age, sex, race, study treatment arm, baseline cigarettes per day, baseline physical activity level, baseline alcohol consumption, smoking status at year one (abstinent or continued smoker), change in weight, and change in glucose, as well as the baseline value of the lipid or lipoprotein dependent variable. 